\title{
Durcet et Sainte-Opportune
}

$\mathrm{n}^{\circ} 3477$

Dominique Cliquet, Jean-Pierre Coutard, Louis-Marie Bocquillon et Denis Toutin

\section{(2) OpenEdition}

\section{Journals}

Édition électronique

URL : http://journals.openedition.org/adlfi/17095

ISSN : 2114-0502

Éditeur

Ministère de la culture

Référence électronique

Dominique Cliquet, Jean-Pierre Coutard, Louis-Marie Bocquillon et Denis Toutin, « Durcet et SainteOpportune », ADLFI. Archéologie de la France - Informations [En ligne], Basse-Normandie, mis en ligne le 23 mars 2016, consulté le 21 avril 2019. URL : http://journals.openedition.org/adlfi/17095

Ce document a été généré automatiquement le 21 avril 2019

(C) Ministère de la Culture et de la Communication, CNRS 


\title{
Durcet et Sainte-Opportune
}

$n^{\circ} 3477$

\author{
Dominique Cliquet, Jean-Pierre Coutard, Louis-Marie Bocquillon et Denis \\ Toutin
}

Lien Atlas (MCC) :

http://atlas.patrimoines.culture.fr/atlas/trunk/index.php?

ap_theme=DOM_2.01.02\&ap_bbox=-0.469;48.716;-0.420;48.763

1 Les prospections conduites par Louis-Marie Bocquillon et Denis Toutain sur le secteur compris entre Briouze et Flers-de-l'Orne ont révélé la présence d'un nouveau site à outils bifaciaux dans le département de l'Orne. L'intérêt de cette découverte est double, en raison de notre quasi-méconnaissance du patrimoine archéologique de ce secteur de l'Orne, d'une part, et du fait que cette implantation se trouve dans un secteur où le silex est absent du sous-sol, d'autre part. Ainsi, le site de Durcet/Sainte-Opportune participe-til à notre connaissance des stratégies d'approvisionnement en matières premières lithiques siliceuses mises en œuvre par les Néandertaliens au Paléolithique moyen, dans le Grand-Ouest. Des sondages visant à appréhender l'état de conservation des niveaux archéologiques et à en préciser la chronologie ont été pratiqués à l'automne 2013, avec l'ouverture de 6 sondages dont le résultat s'est avéré fort décevant, du fait de la déstructuration complète des horizons archéologiques. En effet, la totalité du mobilier se trouve en surface ou incorporée à la partie sommitale des sédiments, dans la semelle de labours. Ce démantèlement des niveaux d'occupation a été maintes fois constaté dans les secteurs où le bilan sédimentaire quaternaire est peu épais, notamment sur les stations de surface de Saint-Julien-de-la-Liègue dans l'Eure.

2 Parmi le mobilier collecté en surface, figurent 1 nucléus en quartz et 7 éclats, ainsi que 3 enlèvements en grès. Cependant ces pièces ne sont pas suffisamment caractéristiques pour savoir si elles se rapportent à l'occupation du Paléolithique moyen, ou à celle du Néolithique aussi attestée sur le gisement. Rappelons que le quartz et le grès, issus du démantèlement des conglomérats, sont présents sur le site. 
3 Le mobilier lithique rapportable au Paléolithique moyen présente divers aspects. Certains enlèvements, dont les éclats Levallois, affichent une altération de "l'épiderme» des pièces beaucoup plus prononcée que la plupart des éclats de confection, par exemple. Ces observations préliminaires mériteront d'être précisées, en fonction des matières premières utilisées et de leur degré d'altération. Cependant, il n'est pas impossible que la collecte de surface corresponde à deux séries rapportables au Paléolithique moyen. Malheureusement, les sondages pratiqués en 2013 n'ont pas permis de répondre à cette question, du fait de la déstructuration du ou des niveau(x) archéologique(s).

4 Les deux ensembles collectés en surface illustrent toutes les étapes de la chaîne opératoire de débitage à l'exception des grands éclats de décorticage. Cela traduirait un séquençage de la chaîne de production, avec dans un premier temps la collecte de la matière première et le nettoyage partiel des blocs de leur cortex, l'emport des blocs, de certains éclats du ou plus vraisemblablement des gite(s) de matière première et leur introduction sur le site de Durcet/Sainte-Opportune.

5 L'assemblage lithique de Durcet/Sainte-Opportune se caractérise donc par une production d'éclats selon divers concepts où figurent la méthode Levallois et une chaîne de façonnage d'outils bifaciaux (bifaces, bifaces partiels et racloirs bifaciaux). Les outils sur éclats de débitage et de façonnage comportent principalement des racloirs.

La série lithique de Durcet/Sainte-Opportune est mal datée. Si les artefacts se rencontrent principalement en surface, les deux quartz taillés découverts dans le sondage 4 de Durcet à $70 \mathrm{~cm}$ de profondeur et le silex taillé trouvé à $25 \mathrm{~cm}$ de profondeur (base de la couche arable) dans le sondage A de Sainte-Opportune plaideraient en faveur d'un démantèlement des niveaux archéologiques durant les pléniglaciaires inférieur et moyen. De ce fait l'industrie serait rapportable au début du Pléistocène supérieur (stade isotopique 5 ou début 4 ).

7 Enfin, rappelons l'intérêt du site pour l'approche des comportements des paléolithiques par rapport à la matière première. En effet, l'apport de la matière première et d'objets en matières exogènes a été reconnu dans un très petit nombre de sites normands, en raison de l'abondance du silex dans les formations superficielles de la Normandie sédimentaire :

- sur le site de travaux de boucherie de Ranville (Calvados), daté d'environ 230 ka, où les outils confectionnés dans du silex de Saint-Pierre-du-Mont ou du silex de la Malière ont été introduits sur le site, puis pour certains remportés ;

- dans l'habitat en doline de Grossoeuvre (Eure) occupé durant l'interglaciaire eemien (vers $130 \mathrm{ka}$ ) où des matières premières exogènes ont été apportées soit sous forme de blocs épannelés, soit sous forme d'éclats prédéterminés, soit enfin sous forme d'outils ;

- à Étoutteville (Seine-Maritime) où trois pièces s'individualisent de l'ensemble : un fragment distal de racloir, une grande lame et un éclat cassé. Elles sont issues d'un silex à grain fin, légèrement moucheté, de structure très homogène, assez gras et brillant, et patiné, gris bleu-pâle du Crétacé supérieur. 


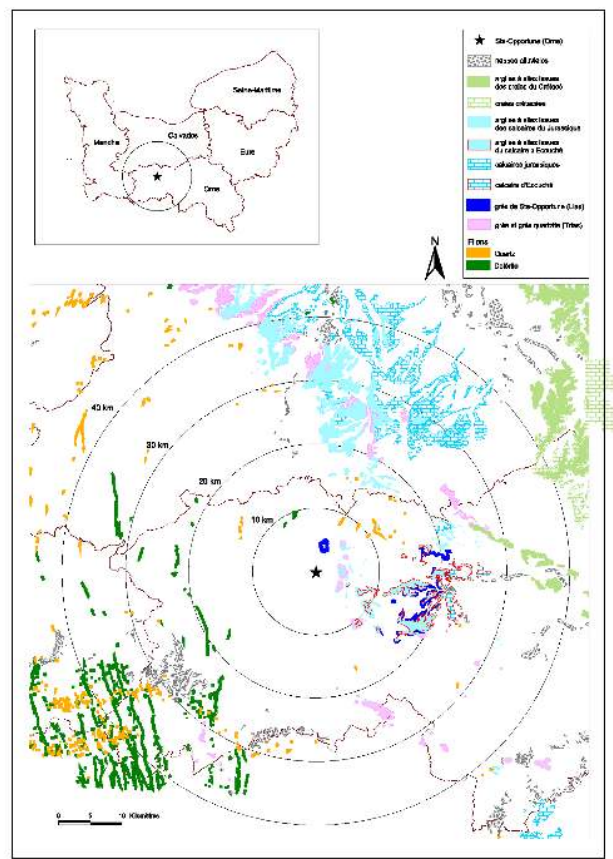

Fig 01

Gîtes potentiels de matières premières

DAO : Anne Ropars (SRA Basse-Normandie).

INDEX

Index chronologique : Paléolithique

Mots-clés : silex, outils, débitage

operation Sondage (SD)

Index géographique : Basse-Normandie, Orne (61), Durcet, Sainte-Opportune

AUTEURS

DOMINIQUE CLIQUET 